\title{
Mapping Out Gender Power: A Bourdieuian Approach
}

\section{Chyun-Fung Shi}

\begin{abstract}
Sexual differences are neither essences nor simple signifiers, neither a matter of realism nor of nominalism, but a matter of social practice. (Toril Moi 1991: 1034)
\end{abstract}

The ideas, concepts and theories underlying the feminist movement have been discussed for more than a century. With the works of Mary Wollstonecraft, Simone de Beauvoir, Gayatri Spivak and many others, feminist theorists, despite their different approaches, have worked together to provide reasons for and answers to the question of why women have been oppressed, repressed and suppressed. Although feminists share the common ground of domination by men, there are continuous debates and dialogues about finding a best way to connect women of different colors and cultural backgrounds, so that one day we can truly change reality and celebrate the emancipation and liberation of women.

As R. Tong (1989) acknowledged, any unitary theory runs the risk of eroding or even erasing the differences between women. Whether we need yet another theory of feminism is itself open for debate. I believe that we do need a more concrete and specific analysis, which provides strategic as well as theoretical feminist perspectives on social and cultural reproduction of gender identity, particularly some approaches that can be applied to the media world that we live in. To be both analytic and strategically practical should be the criteria for the contemporary feminist struggle in our daily practices. ${ }^{1}$

One theoretical approach which will be useful in terms of the two criteria mentioned above is Pierre Bourdieu's recognition that theoretical narratives and political practices are embedded in social relations (L. McCall 1992: 837), or in Bourdieu's own words "constructivist structuralism" or "structuralist constructivism" (1990b: 123) which emphasizes the dialogue between the objective representation of daily practice and the subjective meanings of a social agent's habitus. Here I link this theory to a feminist perspective by focusing on the concepts of body and language, for which I find Bourdieu's triangular interaction between habitus, field and capital can help to map out the relations and meanings of our daily practice and the operation of power. As I suggest, Bourdieu's approach represents an opening into the ways in which we can illustrate maps to show the logic of women's practice within media.

Bourdieu attributes social agents' daily practices to the objective and subjective performances of a set of dispositions which each agent possesses in various social spaces of struggle. Society is a result of interactions between social agents, 
through language, culture, personal emotion, thoughts and the like. Society is perceived through agents' performance and game-play in various fields:

The mind born of the world of objects does not rise as a subjectivity confronting an objectivity: the objective universe is made up of objects which are the product of objectifying operations structured according to the very structures which the mind applies to it. The mind is a metaphor of the world of objects which is itself but an endless circle of mutually reflecting metaphors. (Bourdieu 1977a: 91)

Therefore, social agents' cognition emerges from two different kinds of conditions of existence: objectively classifiable conditions, the "class of conditionings," and position in the structure of conditions, "a structuring structure" (Bourdieu 1984: 171). Here he points out the conflicts and constraints of social agents when they take roles and play the roles out. The theory proposes a dynamic and non-dichotomous notion of the interplay of biological and social reproduction which is necessary in understanding women's social position in terms of gender power relation.

For Bourdieu, the objective appropriation and subjective perception of agents' position in a field are accomplished through habitus, which is a system of schemes of perception and thought formed over time. It is "necessity internalized and converted into a disposition that generates meaningful practices and meaning-giving perceptions; it is a general, transposable disposition which carries out a systematic, universal application-beyond the limits of what has been directly learnt-of the necessity inherent in the learning conditions" (Bourdieu 1984: 170). Habitus is built on the presupposition that a field is the condition of its own possibility (Judith Butler 1999: 117). We perceive and do not perceive the effects of habitus, which is like the air we need to breathe for survival and guides our daily practices in "fields," spaces of struggle for legitimization through calculating and recognizing each other's dispositions and objective and subjective resources.

The performance and practice of habitus can be analyzed through the body and linguistic presentations which are our most visible daily practices. The practices of body and linguistic adaptation in a given field transmit a social agent's habitus within the field. All symbolic manipulations of body experience tend to relate body space with natural space in terms of the same concepts (Bourdieu 1977a: 91). The body plays what it believes and it "enact[s] the past, bringing it back to life" (Bourdieu 1990a: 73).

As Butler sees it, the habitus of body is generated by the "tacit normativity that governs the social game in which the embodied subject acts." (1999: 115). The body habitus is, hence, both subjective and objective; it appropriates and is incorporated with the game-rule-like characters through its daily practices based on its memory and "knowingness" of the generative doxa of the body habitus in a given game.

Indeed, our daily practice of diet, dress, hairstyle, exercise and other practices which constitute self-identity are incorporated with the doxa in fields which reflect how we perceive and appropriate our body habitus. A social agent, "insofar as it is necessarily embodied, and the body is itself the site of 'incorporated history, is not set over and against an 'objective' domain, but has that very 'objectivity' incorporated as the formative condition of its very being" (Butler 1999: 110). It seems reasonable then to argue that biologically and socially, 
gender melts into the formation of habitus of a social body. The body of every single agent by "common sense" carries one gender identity, the identification of which becomes self-evident for each participant in a given field. The process of identification keeps its magical harmony with the agents believing in its doxa. We appropriate our own and other agents' body performances, for example, imposing style and taste judgments on our gendered bodies, in accordance with the generative doxa. The habitus of our body is engendered.

Linguistic performances, as forms of practice, are also the consequence of the dialogues between habitus and a field where social determinations of discourses are received. "[T]he material conditions of existence determine discourse through the linguistic production relations which they make possible and which they structure. For they govern ... also relations in which discourse is genderated" (Bourdieu 1977b: 653). Linguistic utterances as forms of practice and indexes of power and authority compete for legitimization and recognition that is based in "institutional conditions" that produce and receive the linguistic acts. Examining Bourdieu's performative speech acts, Butler further argues that "the performative is not merely an act used by a pregiven subject, but is one of the powerful and insidious ways in which subjects are called into social being, inaugurated into sociality by a variety of diffuse and powerful interpellations" (1999: 125). This is actually what Bourdieu proposed about the dilemma and dialectic of structure and practice.

As a medium of institutional authority, linguistic practice (i.e. accent, vocabulary, manner of uttering and the like) reflects and reinforces the dispositions and social background a social agent possesses. It highlights the differences and opposition between social groups. Each group and class sharing similar linguistic habitus interacts with each other by performing expected speech action or confronting heterodoxic linguistic practices. While this knowingness gives the agent cues of what and how to utter in a field the objective rule-like characters of the game silently insinuate into the agent and are reflected in linguistic performance.

Through linguistic utterance, we perceive each other's disposition and are usually able to appropriate what a discursive field offers. Linguistic practice is valued, for it serves as a cue to "feel" and evaluate the composition of the forms of capital agents possess which further affects and encourages the accumulation and exchange of capital. In a society where women are expected to talk in a certain manner and think using a certain logic, our utilization of capital is constrained. Our "feminine" linguistic capacity and capability, mainly resulting from the socially constructed dispositions of linguistic habitus, are constrained and devalued in the linguistic field according to the doxa.

What then is the operation of a social agent's gendered habitus? How can we map out the meanings of women's daily practices affected and affecting gendered habitus through body and linguistic performances in a given field? What is the practice of gender power in the discursive field, i.e. the media field? Although Bourdieu's theoretical development comes mainly from his research in Algeria and France, his conceptualization of capital accompanied with habitus playing out in a given field can be applied broadly to feminist studies in a wide variety of cultures. What I mean is that Bourdieu's findings propose a hierarchical distribution and evaluation of capital possessed by females on cultural differences. Hence the theory can be applied flexibly 
according to Bourdieu's logic of practice: daily practice is a result of the dialogue between field and habitus which is intertwined with capital (Bourdieu 1984: 101). Epistemologically, Bourdieu's elaboration of structure and practice provides guidance for practical strategies in our daily struggle against males by means of mapping out our own society's power relations based on the logic of practice.

What then are women's media practices? How do women practice their linguistic performances? How is the female body embodied within the media? To begin answering these questions, we can divide media into three fields: a production and organizational field, a creative text field and a decoding/ encoding field. Each field interacts with the others as social agents, such as producers, actors and actresses or audience members, perceives and appropriates the doxa of each field and competes for symbolic capital and the power of legitimization. The gender identification and identity and power relations of women and men within the media's three fields are in an ongoing process of forming and reforming. Therefore, we may propose that the female agents who read romance novels to express disappointment, or as an act of empowerment (Janice Radway 1987), are demonstrating their perception and re-appropriation of gender norms crossing fields, for example, the media decoding/encoding field and the domestic and work fields. Is it not through the practice of engendered habitus in the text decoding/encoding field that females show a passive and private resistance, as reflected in gendered dispositions, which is a silent performantive act of heterodoxy against doxa?

In other words, each society has its own hierarchy of treasuring and measuring resources and forms of capital based on its own priorities. There are conditions and situations for each society to weigh and rank gender, race, class or nationality. Also, each field is likely to have its own logic of capital production and reproduction. As a result, the possession and practice of capital (cultural, economic, social and symbolic) are weighted and appropriated differently between females and males. The same combination and amount of capital therefore does not necessarily acquire similar social space in different fields. Bourdieu's work has some shortcomings which are relevant to feminist implications $^{2}$ (McCall 1992; L. McNay 1999). Still, the work is widely recognized to provide other reflexive insights into current feminist theories ${ }^{3}$ (McCall 1992; McNay 1999; Moi 1991). Methodologically, Bourdieu's research practice may release some of the tension between mainstream feminist theories dominated by Western, white perspectives, and feminist theories based in other cultures. Also, his "intertextual" application is likely to encourage feminists who have been searching for methods which can discern both the examination of reality and conceptualization practice provides guidance for practical strategies in our daily struggle against males by means of mapping out our own society's power relations based on the logic of practices. It allows us, as McNay sees by relating Bhabha's "hybridity" to Bourdieu's "regulated liberties," to understand the "hybrid" forms of women's autonomy (1999: 104). ${ }^{4}$

It is important for us to record the distribution and allocation of capital and practice of habitus of women in fields in a strategic way. Through elaborating the logic of practice, the ongoing social contestation and reformulation of gender perception and appropriation can be recorded. To rearticulate a map of the history of women's struggle through which analyses of the allocation of social, 
economic, cultural and political and of the logics of practices of capital and dispositions can be illustrated. It is an important project for feminist scholarship.

\section{Notes}

1. From the publications of Wollstonecraft and Simone de Beauvoir to today's diversity of feminist studies, conceptualizing women's oppression has been a characteristic of this field. However, conceptualizing connections between critical analysis and strategic practice is less of a concern in the scholarship community.

2. For example, McCall suggests that Bourdieu constructs "the universal power of gender symbolism too rigidly and deterministically" (1992: 847). For McNay, Bourdieu's acknowledgment of potentially subversive effects arising from diverse fields "fails to consider what this might imply for an understanding of modern gender identity" (1999: 106).

3. Moi shows that one advantage of Bourdieu's theory on feminism is that it permits the grasp of "the immense variability of gender as a social factor" (1992: 1035). McNay sees Bourdieu's concepts of habitus and fields as having implications in the context of differentiated power relations (1999: 113-114). McCall notes several advantages of the conceptualization of a feminist habitus epistemologically and methodologically (1992: 860).

4. See, for example, McNay (1999: 104-105) and references therein.

\section{References}

Bourdieu, Pierre. 1977a. Outline of a Theory of Practice. Trans. R. Nice. Cambridge: Cambridge University Press.

Bourdieu, Pierre. 1977b. "The Economy of Linguistic Exchanges." Social Science Information 16(6): 645-668.

Bourdieu, Pierre. 1984. Distinction: A Social Critique of the Judgment of Taste. Trans. R. Nice. Cambridge: Harvard University Press.

Bourdieu, Pierre. 1990a. The Logic of Practice. Trans. R. Nice. Stanford: Stanford University Press.

Bourdieu, Pierre. 1990b. In Other Words: Essays Towards a Reflexive Sociology. Stanford: Stanford University Press.

Butler, Judith. 1999. "Performativity's Social Magic," in R. Shusterman (ed.) Bourdieu: A Critical Reader, pp.113-128. Malden, MA: Blackwell.

McCall, L. 1992. "Does Gender Fit? Bourdieu, Feminism, and Conception of Social Order." Theory and Society 21: 837-867.

McNay, L. 1999. "Gender, Habitus and the Field: Pierre Bourdieu and the Limits of Reflexivity." Theory, Culture \& Society 16(1): 95-117.

Moi, Toril. 1991. "Appropriating Bourdieu: Feminist Theory and Pierre Bourdieu's Sociology of Culture." New Literary History 22(4): 1017-1049.

Radway, Janice. 1987. Reading the Romance. London: Verso.

Tong, R. 1989. Feminist Thought: A Comprehensive Introduction. Boulder: Westview.

Chyun-Fung Shi (PhD, Mass Communications, Temple University) is an Associate Professor in the Advertising Department at Fu-Jen University in Taiwan. 